\title{
Resistance of Aedes aegypti from the State of São Paulo, Brazil, to Organophosphates Insecticides
}

\author{
Maria de Lourdes G Macoris/ ${ }^{+}$, Maria Teresa M Andrighetti, Luiz Takaku, \\ Carmen M Glasser*, Vanessa C Garbeloto, José Eduardo Bracco**
}

\author{
Núcleo de Pesquisa, Serviço Regional, Sucen, Av. Santo Antonio 1627, 17506-040 Marília, SP, Brasil *Diretoria de Combate a \\ Vetores **Laboratório de Bioquímica e Biologia Molecular de Vetores, Sucen, São Paulo, SP, Brasil
}

Since the reintroduction of Aedes aegypti in the state of São Paulo, in the middle of the 1980-decade, organophosphate insecticides are being used to control the dengue vector. In 1996, an annual program for monitoring the susceptibility of Ae. aegypti to the insecticides was implemented. Some of the results of this monitoring program are presented. Ae. aegypti populations from ten localities have been submitted to bioassays with the diagnostic dose of temephos and fenitrothion. Only two (Marilia and Presidente Prudente) remain susceptible to both insecticides and one (Santos) exhibits true resistance. Ae. aegypti from the remaining localities showed an incipient altered susceptibility. Resistance ratios varied from 1.2 to 2.9 for temephos and from 1.5 to 3.2 to fenitrothion, indicating moderate levels of resistance. Biochemical assays did not detect alterations in the enzyme acetilcholinesterase, but indicated that resistance is associated with esterases.

Key words: Aedes aegypti - insecticide - resistance - control - bioassay - organophosphate - esterase

Dengue is a mosquito-borne infection, which in recent years has become a major international public health concern. The global prevalence of the disease has grown dramatically in recent decades. About two fifths of the world's population are now at risk of catching dengue according to the World Health Organization (WHO 2003). At present, the only method of controlling or preventing dengue and dengue haemorrhagic fever (DHF) is to combat the vector mosquitoes. Thus insecticide resistance represents a threat for the efficacy of vector control. Aedes aegypti is resistant to DDT in almost every part of the world in which this species is present, except some African countries. Organophosphate resistance is widespread in the Caribbean region and neighbor countries including Central and South America and pyrethroid resistance has been documented in Asia as well as in the Caribe (WHO 1992).

In 1985, vector surveillance detected the presence of Ae. aegypti in 30 towns of the state of São Paulo. Since then, the number of infested localities has grown. In May 2001 out of 645 towns, 478 (74.1\% of the total) were considered infested and dengue transmission was confirmed in 154 of these (Centro de Vigilância Epidemiológica, CVE 2002).

The first version of an Ae. aegypti Control Plan for São Paulo State started in 1985 (State department for Disease Control, Superintendência de Controle de Endemias, Sucen, internal report 1985). From that time organophosphate insecticides are being used to control the dengue vector. For routine vector control, larval foci were treated with the larvicide temephos and residual perifocal spraying with fenitrothion was recommended for adult control.

Financial support: Superintendência de Controle de Endemias ${ }^{+}$Corresponding author. Fax: +55-14-433.1080. E-mail: macoris@sucen.sp.gov.br

Received 4 December 2002

Accepted 28 May 2003
Space spraying was also used in the Control Program, malathion being used from 1985 to 1992 .

In 1996, Sucen implemented an annual program for monitoring the susceptibility of Ae. aegypti to insecticides in São Paulo. In 2000, in addition to larval and adult bioassays, biochemical tests were included to evaluate the levels of esterase and acetylcholinesterase activity, two enzymes associated with organophosphate resistance (Hemingway \& Ranson 2000). The results of this monitoring program are now presented.

\section{MATERIALS AND METHODS}

Sampling of mosquito populations - Ten towns were chosen for the mosquito sampling according to the intensity of insecticide use, to the number of dengue cases or to their localization in relevant economical areas. The locations are illustrated in Fig. 1. In each of the selected towns, egg samples of mosquitoes were collected using ovitraps (Fay \& Eliason 1966). Ovitraps were set in a grid pattern (Jakob \& Bevier 1969) with the size of the city and the number of ovitraps determining the grid spacing. The number of ovitraps was determined using the guidelines of the National Program for Monitoring susceptibility of Ae. aegypti and varied from 100 to 200 (Ministério da Saúde/Fundação Nacional de Saúde 1999). Only a São Paulo neighborhood was included in the sampling (Pirituba).

Ovitraps were installed during 4 weeks in the second semester of 1999 and were monitored weekly. Clutchs of eggs were collected and used to create laboratory colonies for testing. Each colony was settled with at least 3000 mosquitoes from each city. The first generation of eggs obtained in the laboratory (F 1) was used in the tests.

Biological assays - Biological assays were performed essentially according to the World Health Organization Guidelines (WHO 1976, 1981) to detect and quantify resistance. The susceptible Rockefeller strain, kindly provided by the CDC's laboratory in Puerto Rico, was used 


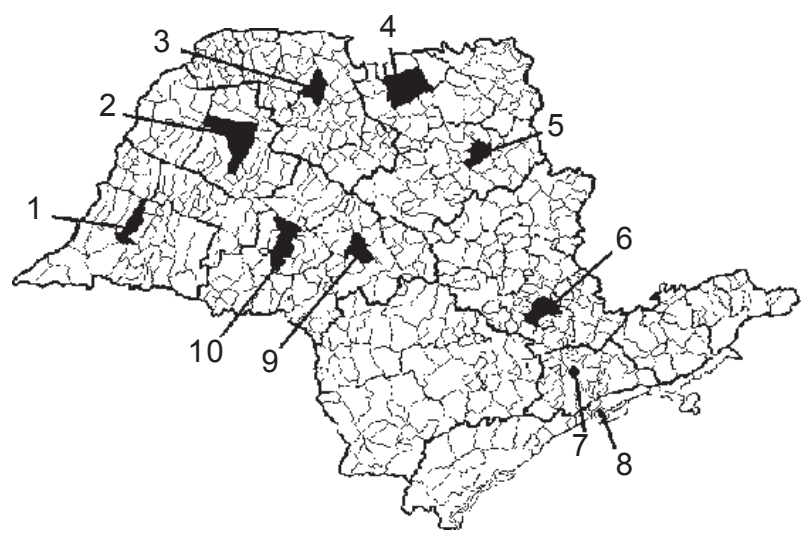

Fig. 1: state of São Paulo municipalities where populations of Aedes aegypti were sampled. 1 Presidente Prudente; 2 Araçatuba; 3 São José do Rio Preto; 4 Ribeirão Preto; 5 Barretos; 6 Campinas; 7 São Paulo (Pirituba); 8 Santos; 9 Bauru; 10 Marília

for calibration of the assays.

The diagnostic doses used for temephos and fenitrothion, $8 \mu \mathrm{g} / \mathrm{l}$ and $10 \mu \mathrm{g} / \mathrm{l}$, respectively, corresponded to twice the lethal concentration 99\% (LD99) for this susceptible strain (WHO 1976).

A total of 800 larvae from each population were exposed in four tests to a diagnostic dose.

For the estimation of lethal concentrations three tests were performed using a range of eight concentrations. In each concentration, 25 larvae were exposed in four replicates per test.

Estimation of lethal concentration $95 \%$ and confidence limits were calculated at the $95 \%$ probability level ( $\mathrm{g}$ test) (Polo-PC 1987) and used for the final analysis.

Biochemical tests - Fourth instar-larvae (F1 generation), frozen at $-70^{\circ} \mathrm{C}$, were used for the assays. The homogenizations were done on ice. All the assays were performed in 96-well microplates and the absorbance was measured on the Microwell Systen Reader 230S (Organon Teknika).

Esterase tests - The protocol for esterase tests was described by Hemingway and Georghiou (1984) and modified by Bracco et al. (1999). Each larva was individually homogenized in $200 \mu \mathrm{l}$ de-ionized water with phenylthiocarbamide (PTC) $1 \mathrm{mM}$ and two $50 \mu \mathrm{l}$ aliquots of each homogenate were placed in two wells of a reading plate. Two hundred $\mu 1$ of $0.03 \mathrm{mM} 1$ or 2-napthyl acetate was added to each well. After $30 \mathrm{~min}$ incubation at $30^{\circ} \mathrm{C}, 50 \mu \mathrm{l}$ of a solution of $0.03 \mathrm{mM}$ tetrazotized o-dianisidine, zinc chloride complex (Fast Blue), 3590 sodium dodecyl sulphate (SDS) was added and samples were read 5 min later at $620 \mathrm{~nm}$. A $1 \mathrm{mM}$ PTC solution replaced mosquito homogenate for the blank sample. At least 178 individuals per population were analyzed.

Acetylcholinesterase test - The methodology described by Bourguet et al. (1997) was used. Individual larvae were homogenized in $400 \mu 1$ of $1 \mathrm{mM}$ phosphate buffer $0.1 \%$ pH 7.0 Triton X-100. Two $100 \mu$ laliquots were placed in adjacent wells. Each well received, alternatively,
$10 \mu 1$ of ethanol or $10 \mu 1$ of $5 \times 10^{-2} \mathrm{M}$ propoxur in ethanol. After incubation for $15 \mathrm{~min}$ at room temperature, $100 \mu \mathrm{l}$ of $0.2 \mathrm{mM}$ dithio-bis 2-nitrobenzoic acid, $0.2 \mathrm{mM}$ acetylthiocholine iodide solution $\mathrm{pH} 7.8$ were added.

Readings were made after 5 and $15 \mathrm{~min}$ at $405 \mathrm{~nm}$. Activity was evaluated as the increase in absorbance between both time points. Ninety-six individuals were analyzed for each population.

Protein dosage - Total protein quantification of mosquito homogenates was performed with the Bio-Rad Protein Assay Kit (Bio-Rad Laboratories) and used to correct esterase activity. Bovine serum albumin was used as a standard.

\section{RESULTS}

The interpretation of results of tests using diagnostic doses was based on the criteria proposed by Davidson and Zahar (1973). The mosquito population was considered susceptible if the average percentage of mortality was $>98 \%$, resistant if mortality was below $80 \%$ and in an intermediate situation indicating incipient resistance when mortality was in the range $80-98 \%$. The results presented in Table I show that only Marília and Presidente Prudente Ae. aegypti populations are susceptible to both temephos and fenitrotion. The Bauru population is susceptible to temephos and Campinas mosquitoes remain susceptible to fenitrothion. An altered response for both insecticides was recorded in Araçatuba, Barretos, Ribeirão Preto, São José do Rio Preto and Pirituba while mosquitoes from Santos were classified as resistant for both insecticides. In the estimation of the resistance ratio, a similar pattern of response of the populations was observed. The populations of Ae. aegypti from Presidente Prudente, Marília and Bauru showed the smallest resistance ratios as already observed in 1998 (Macoris et al. 1999). There is a gradient response for populations that had an altered response in diagnostic dose tests and the mosquitoes from Santos, which were classified as resistant in the diagnostic test, showed the highest resistant ratio for both insecticides.

The results of the biochemical tests for the evaluation of the acetylcholinesterase activity are expressed as the frequency of resistant allele present in the populations and are listed in Table II. It was noted that the resistant allele is present in some populations but always at a low frequency. The results of biochemical tests where activity of $\alpha$ - and $\beta$-esterases were evaluated are in Table III and Figs 2 and 3. There is a wide variation on the results, which are related to the variations observed in the biological assays. The populations of Ribeirão Preto, São José do Rio Preto and Santos showed the higher variance for $\alpha$-esterase activity (Table III, Fig. 2). For $\beta$-esterase activity, the populations that showed the greatest variance were Araçatuba, Campinas, Pirituba, Ribeirão Preto and Santos (Table III, Fig. 3).

\section{DISCUSSION}

The bioassays seem to be reliable since there was an agreement in the results of both diagnostic tests and estimation of resistant ratios. The populations that were 
TABLE I

Bioassays with Aedes aegypti larvae from towns of the state of São Paulo with the organophosphates temephos and fenitrothion

\begin{tabular}{|c|c|c|c|c|c|c|}
\hline \multirow[b]{2}{*}{ Population } & \multicolumn{3}{|c|}{ Temephos } & \multicolumn{3}{|c|}{ Fenitrothion } \\
\hline & $\%$ mortality at DD & LC $95(\mu \mathrm{g} / 1)$ & $\mathrm{RR}$ & $\%$ mortality at DD & LC $95(\mu \mathrm{g} / 1)$ & RR \\
\hline Araçatuba & 97 & 7.4 & 2.2 & 92 & 8.2 & 2.2 \\
\hline Barretos & 94 & 8.0 & 2.4 & 94 & 9.3 & 2.4 \\
\hline Bauru & 100 & 5.0 & 1.5 & 94 & 5.7 & 1.5 \\
\hline Campinas & 91 & 9.0 & 2.6 & 99.5 & 7.1 & 1.9 \\
\hline Marília & 100 & 5.7 & 1.7 & 100 & 6.9 & 1.8 \\
\hline Presidente Prudente & 100 & 4.1 & 1.2 & 100 & 5.9 & 1.6 \\
\hline Pirituba (SP) & 85 & 8.5 & 2.5 & 95 & 9.9 & 2.6 \\
\hline Ribeirão Preto & 88 & 9.5 & 2.8 & 94 & 10.0 & 2.6 \\
\hline São José do Rio Preto & 96 & 8.0 & 2.4 & 97 & 10.2 & 2.7 \\
\hline Santos & 79 & 10.0 & 2.9 & 75 & 12.0 & 3.2 \\
\hline Rockefeller & - & 3.4 & - & - & 3.8 & - \\
\hline
\end{tabular}

DD: diagnostic dose for temephos and fenitrothion was 8 and $10 \mu \mathrm{g} / 1$ respectively; LC: lethal concentration 95\%; RR: resistance ratio related to the susceptible strain, Rockefeller

\section{TABLE II}

Frequency of the acetylcholinesterase resistant allele $\left(\right.$ Ace $\left.^{\mathrm{R}}\right)$ in Aedes aegypti populations of the state of São Paulo, Brazil (96 individuals per population)

\begin{tabular}{lc}
\hline Population & $\mathrm{F}_{\left(\text {Ace } \mathrm{R}_{\text {) }}\right.}$ \\
\hline Rockefeller & 0.000 \\
Araçatuba & 0.000 \\
Barretos & 0.003 \\
Bauru & $\overline{0}$ \\
Campinas & 0.000 \\
Marília & 0.011 \\
Presidente Prudente & 0.011 \\
Pirituba & 0.008 \\
Ribeirão Preto & 0.000 \\
São José do Rio Preto & 0.027 \\
Santos & 0.005 \\
\hline
\end{tabular}

_. data not available classified as susceptible in the diagnostic tests were the ones that showed resistant ratios below 2 . The ones classified with incipient resistance showed resistance ratios between 2 to 3 while the population classified as resistant in the diagnostic test showed resistance ratio $>3$.

Among the ten cities where mosquitoes were sampled, only two remain susceptible to both temephos and fenitrothion (Marília and Presidente Prudente). In all the others, small alterations were observed and in only one (Santos) the Ae. aegypti population was classified as resistant. The level of resistance observed however is low, compared to the resistance ratios of over 20 reported by Rawlings (Rawlings \& Ragoonansingh 1990, Rawlins \& Wan 1995, Rawlins 1998) in the Caribbean area.

The resistant form of acetylcholinesterase is present in a very low frequency in the populations of this study and might not be responsible for the alterations observed in the biological tests. In fact, the presence of the resis-

TABLE III

Increase, average, standard deviation and variance of elevated $\alpha$ - and $\beta$-esterase activity

\begin{tabular}{|c|c|c|c|c|c|c|c|c|}
\hline \multirow[b]{2}{*}{ Population } & \multicolumn{4}{|c|}{$\alpha$-esterase } & \multicolumn{4}{|c|}{$\beta$-esterase } \\
\hline & Increase & $\chi$ & $\sigma$ & $\sigma^{2}$ & Increase & $\chi$ & $\sigma$ & $\sigma^{2}$ \\
\hline Rockefeller & - & 1.49 & 0.46 & 0.21 & - & 3.02 & 1.82 & 3.31 \\
\hline Araçatuba & + & 4.16 & 1.78 & 3.18 & + & 4.23 & 4.75 & 22.58 \\
\hline Barretos & - & 1.32 & 0.54 & 0.29 & - & 0.83 & 1.36 & 1.85 \\
\hline Campinas & - & 2.97 & 1.63 & 2.64 & + & 4.43 & 3.29 & 10.83 \\
\hline Marília & - & 3.27 & 0.76 & 0.58 & - & 3.83 & 2.13 & 4.55 \\
\hline Presidente Prudente & - & 2.37 & 0.55 & 0.30 & - & 3.95 & 2.92 & 8.54 \\
\hline Pirituba - SP & - & 2.56 & 1.66 & 2.77 & + & 4.86 & 12.32 & 151.84 \\
\hline Ribeirão Preto & + & 7.10 & 15.64 & 244.9 & + & 8.32 & 20.39 & 415.66 \\
\hline São José do Rio Preto & + & 4.07 & 3.70 & 13.69 & - & 0.79 & 1.67 & 2.79 \\
\hline Santos & + & 6.58 & 3.80 & 14.44 & + & 10.52 & 7.99 & 63.81 \\
\hline
\end{tabular}

+ :elevation of activity when compared to the reference strain Rockefeller; -: pattern of activity similar to the reference strain; $\chi$ : average; $\sigma$ : standard deviation; $\sigma^{2}$ : variance 

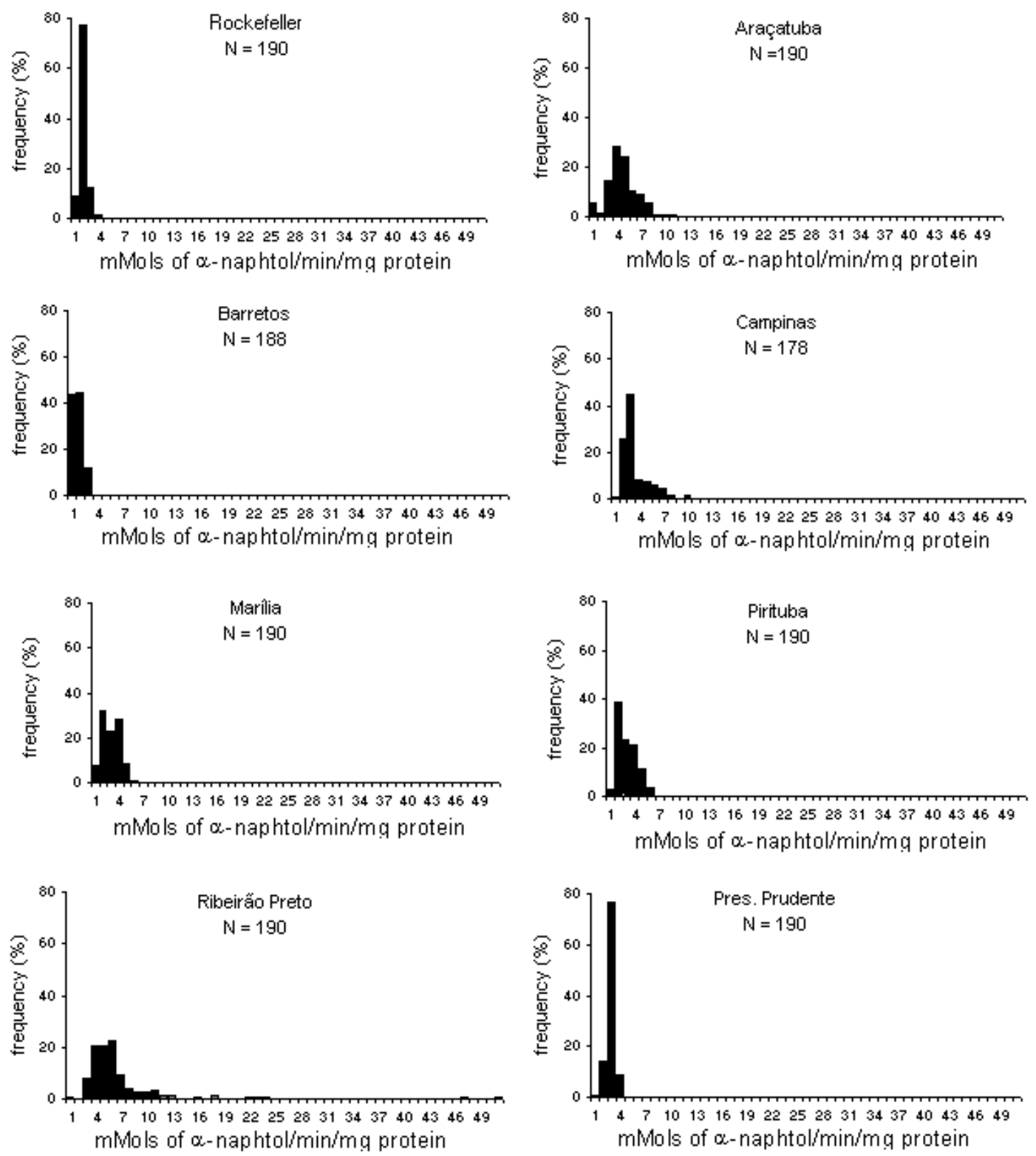

Fig. 2: frequency of $\alpha$-esterase class activity in Aedes aegypti populations of the state of São Paulo, Brazil

tant allele was reported just in one population of $A e$. aegypti from Santiago de Cuba but the authors demonstrated that this mechanism was not involved in that population's insecticide resistance. In that area the observed organophosphorus resistance was related rather to esterases and glutathione-s-transferase (Rodriguez et al. 1999).

The field populations of Ae. aegypti with higher levels of $\alpha$ - and $\beta$-esterase activity, were also those that showed higher resistance ratios. Since these enzymes metabolize insecticides from the organophosphate group, they are presumably involved in the resistance mechanisms of those populations. This is compatible with the results presented by Gokhale et al. (2000) who showed that the evolution of resistance to organophosphates was mediated by a 3-4 fold increase in the esterase activity.

The correlation between esterase activity and susceptibility to insecticides makes it possible to establish where resistance is beginning. The high variability of $\alpha-$ and $\beta$ esterase activity observed indicates that resistance is present in only a small part of the population with this high level of activity while the majority of the population has not undergone alteration. This monitoring method is thus sensitive enough to detect the process in its beginning. The results demonstrate the importance of continuing the surveillance in order to and monitor the level and frequency of resistance.

With the exception of Santos the levels of resistance 

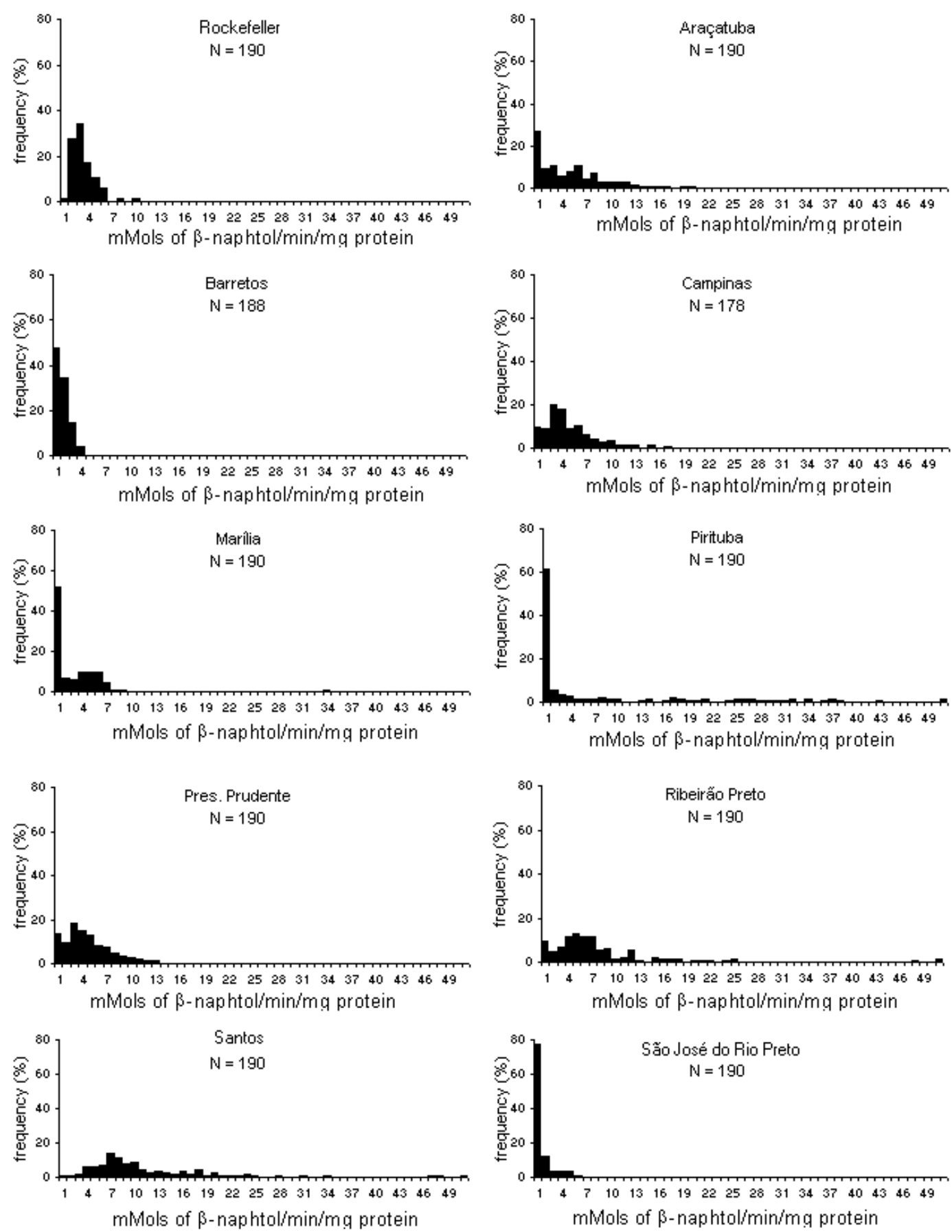

Fig. 3: frequency of $\beta$-esterase class activity in Aedes aegypti populations of the state of São Paulo, Brazil

observed are not indicative of a possible larval control failure in the field. Nevertheless, it is recommended that field tests should be performed to evaluate efficacy of larval control especially in the port of Santos.

\section{ACKNOWLEDGMENTS}

To the technicians Iole Arumi Sei, Kleber José Whitaker and Karina de Cássia Rodrigues Nalon and the Fundap trainee Sérgio Fernando Hennies Leite for their technical assistance.

\section{REFERENCES}

Bourguet D, Pasteur N, Bisset J, Raymond M 1997. Determination of Ace. 1 genotypes in single mosquitoes: toward an ecumenical biochemical test. Pest Biochem Physiol 55: 122129.

Bracco JE, Barata JMS, Marinotti O 1999. Evaluation of insecticide resistance and biochemical mechanisms in a population of Culex quinquefasciatus (Diptera: Culicidae) from 
São Paulo, Brazil. Mem Inst Oswaldo Cruz 94: 115-120.

CVE-Centro de Vigilância Epidemiológica, Secretaria de Estado da Saúde, São Paulo. Dengue (online access in 08/16/2002). Available at http://www.cve.saude.sp.gov.br/htm/ Cve_deng.htm.

Davidson G, Zahar AR 1973. The practical implications of resistance of malaria vectors to insecticides. Bull WHO 49: 475-483.

Fay RW, Eliason DA 1966. A preferred oviposition site as a surveillance method for Aedes aegypti. Mosq News 26: 531535.

Gokhale MD, Jacob PG, Mourya DT 2000. Dengue virus and insecticide susceptibility status of Aedes aegypti mosquitoes from Belagola village, Mandya District, Karnataka state: during and post-epidemic investigations. J Commun Dis 32: 247-253.

Hemingway J, Georguiou GP 1984. Baseline esterase levels for anopheline and culicine mosquitoes. Mosq News 44:33.

Hemingway J, Ranson H 2000. Insecticide resistance in insect vectors of human disease. Ann Rev Entomol 45: 371-391.

Jakob WL, Bevier GA 1969. Application of ovitraps in the U.S. Aedes aegypti eradication program. Mosq News 29: 5561.

Macoris MLG, Andrighetti MTM, Takaku L, Glasser CM, Garbelotto VC, Cirino VCB 1999. Alteração de resposta de suscetibilidade de Aedes aegypti a inseticidas organofosforados em municípios do Estado de São Paulo, Brasil. Rev Saúde Públ 33: 521-522.

Ministério da Saúde. Fundação Nacional de Saúde 1999. Reunião Técnica para discussão do status de resistência de Aedes aegypti e definir estratégias a serem implantadas para monitoramento da resistência no Brasil. Relatório final, unpublished document, $30 \mathrm{pp}$.

Polo-PC: Probit or Logit analysis [software]. Berkeley, CA, Leora Software, 1987.
Rawlins SC 1998. Spatial distribution of insecticide resistance in Caribbean populations of Aedes aegypti and its significance. Rev Panameña de Salud Publica 4: 243-251.

Rawlins SC, Ragoonansingh R 1990. Comparative organophosphorus insecticide susceptibility in Caribbean populations of Aedes aegypti and Toxorhynchites moctezuma.J Am Mosquito Control Ass 6: 315-317.

Rawlins SC, Wan JO 1995. Resistance in some Caribbean populations of Aedes aegypti to several insecticides. J Am Mosquito Control Ass 11: 59-65.

Rodriguez MM, Bisset JA, Mila LH, Calvo E, Diaz C, Alain Soca L 1999. Levels of insecticide resistance and its mechanisms in a strain of Aedes aegypti of Santiago de Cuba. Rev Cubana Med Trop 51: 83-88.

WHO-World Health Organization 1976. Expert Committee on Insecticide Resistance of Vectors and Reservoirs of Diseases to Pesticides. Criteria and meaning of tests for determining the susceptibility or resistance, unpublished document, annex of $585 \mathrm{WHO}$ technical report series, WHO/ $\mathrm{VBC} / 81.6,4 \mathrm{pp}$.

WHO-World Health Organization 1981. Instructions for determining the susceptibility or resistance of mosquito larvae to insecticides, unpublished document, WHO/VBC/ 81.807, $6 \mathrm{pp}$.

WHO-World Health Organization 1992. Expert Committee on Vector Biology and Control. Vector resistance to pesticides, 818 report, unpublished document, WHO technical report series, $63 \mathrm{pp}$.

WHO-World Health Organization 2003. Dengue (online, access in 03/06/2003). Available at http://www.who.int/inf-fs/en/ fact117.html. 